American Journal of Applied Sciences 5 (11): 1588-1594, 2008

ISSN 1546-9239

(C) 2008 Science Publications

\title{
Applied Issues of Agritourism Cooperation and Sustainable Endogenous Development
}

\author{
${ }^{1}$ Helen Theodoropoulou, ${ }^{1}$ Roido Mitoula, ${ }^{1}$ Olga Astara and ${ }^{2}$ Panagiotis Kaldis \\ ${ }^{1}$ Department of Home Economics and Ecology, \\ Harokopio University, 70 E. Venizelos, 17671 Athens, Greece \\ ${ }^{2}$ Department of Oenology and Beverages Technology, \\ Technological Educational Institute of Athens, Ag. Spyridona, Egaleo, 12210, Athens, Greece
}

\begin{abstract}
This research aims at examining how an agritourism cooperative and its activities promote endogenous development using local human, natural and technological resources in a sustainable way with other local production activities. Technology allows the agritourism cooperative to effectively use local resources and simultaneously to increase its competitiveness in marketing of products. So, the cooperative becomes more competitive in regional and national markets and its economy is connected more closely with the national and international economy.
\end{abstract}

Key words: Sustainable, endogenous development, local development, agritourism cooperative

\section{INTRODUCTION}

The term development denotes the pursuit or the realization of improving the socioeconomic status of people. Local development is the promotion of all economic activities, in which a place presents some advantages, as well as the exploitation of all its wealthproducing sources ${ }^{[1,3,4]}$. The main objective of local economic development is to create local opportunities of employment in sectors that contribute to the improvement of local community, using existing human and natural resources. This means that local actors (organisations, institutions, local enterprises, local business initiatives), are the basic levers of development. Thus, local productivity, traditions and cultural heritage are developed supporting the economic enlargement and the improvement of quality of life of the local people ${ }^{[5,13,15]}$. Sustainability denotes that all these factors are continuously maintained in the present and the future without a deterioration of the quality of life.

Therefore, the endogenous sustainable development aims to develop the territorial advantages of a region but also every activity that takes place with the initiative of the local population ${ }^{[11,14]}$. According to Barquero the endogenous local sustainable development could be a suitable developmental process, in combination with the activation of available resources of a region and its endogenous capacity. This process of economic development and structural change leads to an improvement of the level of life of the local population, which has at least, three dimensions: the economic, the social-cultural and the politicaladministrative $^{[1,7,9]}$.

Undeniably, the planning and implementation of a policy of local development are not easy. Available experience indicates that many plans were developed thanks to the capabilities of local businessmen who undertook the initiative and the management of the new plans by undertaking enterprising risks $\mathrm{s}^{[10]}$.

In this frame, the present study explores whether a local enterprise and more specifically the Agritourism Cooperative of Women of Zagora in Greece can serve as an institution of endogenous viable local development and what are the characteristics and actors that contribute to this goal. Therefore, the aim of this research, taking as a case in point the achieved effort of the Agritourism Cooperative of Women of Zagora, is to lead to certain conclusions and proposals for how endogenous sustainable development can be a serious alternative, that respects natural and human resources and constitutes a more permanent solution in the problem of unemployment than occurs in most local situations.

In order to accomplish the above aim, information and data on the characteristics of the region and the socioeconomic characteristics of its residents were collected by contacting the chairman of the cooperative under study. Subsequently, an empirical approach was drawn through a questionnaire based interview with the chairman of the cooperative. Also, descriptive statistics on socioeconomic characteristics of the members of

Corresponding Author: Helen Theodoropoulou, Department of Home Economics and Ecology, Harokopio University, 70 E. Venizelos, 17671 Athens, Greece Tel: +30-2109549205 Fax: +30-2109577050 
cooperative were used to profile the composition of the cooperative. Finally, based on all the above collected information conclusions were drawn on achieving sustainable endogenous development in the frame of local enterprising initiatives.

\section{MATERIALS AND METHODS}

Study area: Zagora constitutes the biggest village of Mountain Pilion in Central Greece with a population of 2636 residents $^{[8]}$. With regard to the employment of the population in Zagora, economically active are 943, economically not active 1389, unemployed 30 , new unemployed 16 and occupied $913^{[12]}$. The morphology of the region is mountainous with the largest percentage of the area covered by cultivated land and forests. The morphology of the region leads the largest percentage of residents to the agricultural sector. Finally concerning the road network, Zagora is connected with the greater region via a two way paved $\operatorname{road}^{[12]}$.

In the study area local businesses are an essential component of endogenous development. The possibilities of endogenous development result from the availability of local enterprising resources, capable of exploiting local production factors and at the same time to sustain them for the future and to protect the natural and social environment ${ }^{[1]}$. What is however the origin and the starting line of these local businessmen? How are they created? The origin of businessmen varies also and is always connected with local production activities $^{[16]}$. Every time a businessman or a group of businessmen in the region achieves their plans and they are successful, then other enterprises try to imitate them.

In order to overcome the difficulties facing householders-businessmen in the management of local enterprises, it is necessary to establish educational programs that can encourage local enterprising activities and facilitate the growth of enterprises and their consolidation with the beneficial results that this produces. The need for education and training on business issues dexterity is imperative since the educational level of residents is low.

The agritourism cooperative of women of zagora: The founding core of the Agritourism Cooperative of Women of Zagora was the Union of Women of Zagora that was constituted by 40 women. Discussions for the foundation of a cooperative started during the Feast of Apples in 1992 in which a buffet with sweets that had been brought by the women from their houses was presented. Taking into account the economic profit that resulted from their participation with foods and sweets in the buffet and after one year of discussions and consultations in the association in order to attain the required number of women needed for the statute (it should be the 50 founding members), a decision was taken for the first Founding Assembly of Cooperative. The founding occurred in November $1993^{[2,6,8]}$.

The activities of Agritourism Cooperative initially were the production and sale of traditional sweets and marmalades that women members prepared in their houses.

In May of 1995 it was decided to establish a laboratory so they could better serve the customers. Five years later an old Mansion was renovated into an Agritourism lodging with 5 rooms and a modern laboratory created with old type cauldrons in the ground floor of the building.

Finally, the women started to offer catering services. In the frame of Agritourism Cooperative that is constituted by 60 active members the activities carried out are production, manufacturing, commercial and Agritourism activities, as well as catering services.

The Agritourism Cooperative, as mentioned earlier, owns a laboratory for the manufacture of products using fruits produced by the members of the corporation which are: quince, lemon, Pergamon, citron, kiwi, courgette, watermelon, cherry, grape and other fruits and jams. Also, it provides storeroom for the storage of raw material that they use.

The decision on the quantity of production is based on demand from the previous year and estimates for the present. The quantity that will be sold by the cooperative by each member depends on the needs and the number of members that produce the particular product. If more fruits are needed they are bought by other cooperatives such as the Rural Cooperative of Zagora or a producer from Chios. Also they collect herbs, such as oregano, that exist in Mt. Pilion.

Moreover, there is a coffee shop, where they sell the products they prepared. Finally it offers catering services with traditional foods such as pies.

Generally, the Agritourism Cooperative carries out the following operations:

- It assembles the rural products of the region

- It manufactures and packs these products

- Sells the products through various channels (wholesale-retail trade, catering service and the shop of the cooperative)

Another sector of activity of the Cooperative, connected with the previous but with autonomy is the establishment and operation of Agritourism lodging. 
Am. J. Applied Sci., 5 (11): 1588-1594, 2008

Specifically, the renovation of a mansion that became possible with financing by the Community Initiative LEADER in 1998, led to the creation of an Agritourism lodge with a capacity of 5 rooms. The lodge services provided, beyond the overnight stay, include traditional breakfast (with pies and regional sweets), an agreement with tourist offices of the City of Volos has been established for advertisement and promotion of the lodge to guarantee tourist customers.

The operation of the Agritourism lodge is included in the Tertiary sector of services; it is connected however with the more general local development, as it is also analysed further.

Questionnaire survey and data collection: The statistical frame of the study was based on a sample of 29 members of the cooperative under study. Relevant data were collected through a questionnaire survey. The investigators completed the questionnaires by interviewing the members of the cooperative who agreed to participate in the study. The questionnaire comprised three sections namely demographic, educational and employment characteristics. The data collected were analysed by using descriptive statistics.

Data on the operation and administration of the cooperative were provided by the Municipality of Magnisia.

\section{RESULTS AND DISCUSSION}

Profile of the characteristics of the women of the agritourism cooperative of zagora: Based on the data analysis of the 29 questionnaires the majority of respondents age ranged from 30 to 44 years old $(58.6 \%)$. Most of the individuals (82.8\%) classify their main job as being in agriculture and they were self employed $(75.9 \%)$ in the agricultural sector. Most of the respondents $(51.7 \%)$ said they worked at least 10 years in the agritourism cooperative and their occupation in the cooperative is in production $(69 \%)$, administration (20\%) or services $(10 \%)$. Their education level was mostly lyceum (41.4\%), while $27.6 \%$ had finished only primary school. Table 1-6 describe the above data.

Distribution of work and internal bodies of operation: The cooperative is constituted, as it was mentioned above, by 60 active members. There are full time permanent personnel that are occupied: a) in the laboratory in 2 shifts of 5 members (in the event of increasing work load the working members in the laboratory can reach 10) and 1 person in charge of each shift. In total the permanent personnel in each shift can
Table 1: Age of the women of the agritourism cooperative of Zagora

\begin{tabular}{ll}
\hline Age $\quad(\mathrm{n}=29)$ & $(\%)$ \\
\hline $20-24$ & 003.4 \\
$25-29$ & 010.3 \\
$30-44$ & 058.6 \\
$45-50$ & 010.3 \\
$51-55$ & 003.4 \\
$56-65$ & 010.3 \\
$>65$ & 003.4 \\
Total & 100.0 \\
\hline
\end{tabular}

Table 2: Educational level of the women of the agritourism cooperative of Zagora $(n=29)$

\begin{tabular}{ll}
\hline Educational level & $(\%)$ \\
\hline Some classes of primary school & 003.4 \\
Primary school & 027.6 \\
Some classes of high school & 013.8 \\
High school & 010.3 \\
Technical lyceum/ technical schools & 003.4 \\
Lyceum & 041.4 \\
Total & 100.0 \\
\hline
\end{tabular}

Table 3: Sector on which women of the agritourism cooperative of Zagora classify their main job $(n=27)$

\begin{tabular}{ll}
\hline Sector & $(\%)$ \\
\hline House work & 003.7 \\
Agriculture & 088.9 \\
Industry-small industries & 003.7 \\
Health and social welfare & 003.7 \\
Total & 100.0 \\
\hline
\end{tabular}

Table 4: Position that women of the agritourism cooperative of Zagora have in their main job $(\mathrm{n}=24)$

\begin{tabular}{ll}
\hline Job position & $(\%)$ \\
\hline Self employed in the agriculture sector & 091.7 \\
Employed in the private sector & 004.2 \\
Assistant in the family business & 004.2 \\
Total & 100.0 \\
\hline
\end{tabular}

Table 5: Years that women of Zagora have been working in the agritourism association $(\mathrm{n}=28)$

\begin{tabular}{ll}
\hline Years working & $(\%)$ \\
\hline 3 & 010.7 \\
4 & 007.1 \\
5 & 007.1 \\
6 & 010.7 \\
7 & 007.1 \\
8 & 003.6 \\
10 & 053.6 \\
Total & 100.0 \\
\hline
\end{tabular}

Table 6: Occupation that the women of the cooperative of Zagora have in the agritourism association $(n=11)$

\begin{tabular}{lc}
\hline Occupation & $(\%)$ \\
\hline Production & 054.5 \\
Promotion & 018.2 \\
Services & 027.3 \\
Total & 100.0 \\
\hline
\end{tabular}

vary from 6 to 11 members depending on the work load. Employment $\mathrm{h}$ are 8:30-13:30 and 15:30-20:30. 
All members of the Agritourism Cooperative participate in the shifts in rotation ${ }^{[2,6,8]}$.

In the coffee shop, 2 members are occupied, one in the morning and one in the afternoon (in response to work load the number of workers can increase $)^{[2,6,8]}$.

Decision-making, assessment and planning of Cooperative are realised via two bodies: the five member administrative council (that are constituted by the Chairman, the secretary, the cashier and two members) and the Assembly (constituted by all members). The decisions are usually taken by the five member council and in cases of important decisions of economic character the Council proposes and the Assembly decides requiring a quorum of the $2 / 3$ of members ${ }^{[2,6,8]}$.

Relation of cooperative with other local and non local institutions: The cooperative collaborates with the local self-government and other local institutions for the successful organisation and implementation of various cultural events ${ }^{[2,6,8]}$.

With regard to its relations with other Agritourism institutions it is member of the Union of Cooperatives of Women of Greece and the Union of Cooperatives of Greece. This networking provides useful information for the problems and the prospects of Cooperatives in Greece and it cultivates the spirit of solidarity, which should exist between similar enterprising initiatives ${ }^{[2,6,8]}$.

Direct and indirect contribution in the employment: The contribution of the Agritourism Cooperative of Women to employment is direct and indirect. It is direct via the number of women who are the 60 members of the cooperative and via the occupied 2 employees (the accountant and the woman who works as receptionist). The cooperative participates in the employment program Stage and other similar programs.

Indirect employment is related to the cultivation and production of rural products by $80 \%$ of farmersmembers of the cooperative as well as the participation of all members in the manufacture of rural products through the coffee shop and operation of Agritourism lodging.

Indirect contribution in employment at a second level: At a second level its contribution to employment is via its relation with production which leads to a bigger production of rural products and a likely absorption of some products that do not have so much demand in the market.

Finally, the operation of the cooperative constitutes reinforcement of the local market through extension of the cooperative locally and abroad. Exports of products (marmalades) in countries such as Germany and the publicity of Agritourism lodging for vacations result in an increase in the number of visitors and thus financial support of shops and enterprises that provide services such as banks, restaurants, mini markets, gas stations, etc.

\begin{abstract}
Absorption of national and community funds
Internal lending: The economic history of Agritourism Cooperative is related directly to the absorption of national and community funds. At the start it loaned 3000 Euros from the Rural Cooperative of Zagora for the first expenses including payment to a lawyer for drafting the statute, rental for the shop and other expenses. Afterwards it collected a 1200 Euros subsidy of rent from the Prefecture of Magnesia and another 1000 Euros subside from the Agricultural Bank for hiring an employee $e^{[2,6,8]}$.

Community Funds (Community Initiative LEADER): After 5 years they received the first serious subsidy with the integration of the Cooperative into the program Leader for the establishment of an Agritourism lodging via the renovation of a mansion and the creation of a modern laboratory in the ground floor of the same building. The subsidy that was approved was 120000 Euros. The renovation of the building cost much more than anticipated and the difference was covered with self-financing ${ }^{[2,6,8]}$.
\end{abstract}

Sustainability: The sustainability of the cooperative is proved via the converted profits in further investment that resulted in the efficient operation and the development of future prospects: 1) purchase of a car for service of catering, 2) organic cultivation, 3) exploitation of building for the hostel, 4) operation of the restaurant, 5) extension of collaboration with the Rural Cooperative of Zagora.

Another aspect of sustainability is proved by the contribution of the particular cooperative (as a model of local enterprising activity) in local endogenous development. That is to say the development that emanates from the local society developing its own natural and human resources. The results benefit the residents of the local society, so much via contribution to a permanent base for employment as well as to the promotion of the character of the region (its uniqueness) via the sale of traditional products or the services it offers. Accordingly, it prompts the employment of women in more than one activity, a fact that ensures the holding of population, in contrast with regions that present dramatic reduction or even ageing of local population. This results in safeguarding the 
development of the region without dangers of alienation of its traditional character and its natural resources and natural beauty.

\section{CONCLUSIONS}

Does the cooperative correspond to the model of endogenous development?

Based on the above analysis of the study case of Agritourism cooperative and its activities, it is concluded that:

- It promotes endogenous development using local human, natural and technological resources in a sustainable way with other local production activities

- In general terms the cooperative corresponds to the model of endogenous development, in which it possesses an additive and irreplaceable role

More specifically, with regard to the cooperative's role in the model of completed endogenous development, it corresponds to the strategies stipulated by John Ikerd for endogenous local development:

- Investment in human resources after it has succeeded in motivating a large number of women to attend and to be active in the work and the obligations that the cooperative requires of its members

- Investment in infrastructures, as it happens with the Agritourism Cooperative of Zagora, which created the conditions that made it possible to establish a modern laboratory for its manufacturing activities and to purchase a car for transport and distribution of products to the points of sale

- Investment in better quality of life because it promotes the economic development of the region through the promotion of the cooperative and the profits remain in the region which are recycled and they are invested promoting thus local development and accordingly the quality of life. In conclusion, from the points 2 and 3 it results that the added value remains in the region and profits are extended (quantitative and temporally) via investment

- Investment in human relations and mutual understanding for individuals and the cooperative presupposes a climate of communication and collaboration that fosters even further the spirit of the cooperative

- Investment in the maintenance of natural resources. The cooperative is a local enterprise which bases its existence on the maintenance and viable exploitation of natural resources. Contrarily a non local enterprise would attend mainly to its economic profit not taking into account the possibilities of regeneration of natural resources in the region.

- Involvement of all in the realisation of objectives for viable local endogenous development that emerges naturally from large participation

Accordingly the Agritourism cooperative of women plays an important but also additional role in the frame of endogenous development, a fact that appears through the subsidies received in its first steps from other local institutions (prefecture, rural bank) but also afterwards with its integration in the program Leader as well as further prospects of drawing national and Community funds.

The contribution of characteristics of a particular region in the achievement of endogenous development and in the creation of an Agritourism Cooperative.

This local enterprise is connected as mentioned above to an important availability of natural resources that is essential for its manufacturing activities, as well as with the geographic distribution that allows the enterprise to have good access to markets of raw material, final products and production factors.

Besides, the region of Zagora allocates suitable infrastructures with regard to a sufficient and modern road network but also facilitates the access of the enterprise to telecommunications and information banks.

At the same time, it is obvious that the Agritourism cooperative exists to facilitate the proper exploitation of profits that are accumulated by its activities for covering administrative expenses but also for creating new investments.

Finally, the local initiatives that were created in the region (Rural Cooperative of Zagora and other) have their roots in the local trade and craft-based activities which contributed to the creation of an enterprising culture with technological productive and commercial "know how" simultaneously with the creation and reproduction of the working force and businessmen. Also, a powerful culture was created that strengthened the spirit of local identity, which not only influenced positively human resources, but determined also the particular [process of] configuration of the local production system.

The role of agritourism cooperative in the national and international economic system: As it appears in 
the example of the Agritourism cooperative the need for enlargement of markets and to overcome its local and regional character leads to important changes in the methods of production, including the import of new equipment (laboratory with new modern instruments) and the differentiation of their production (transformation of fruits to sweets and marmalades, collection of herbs and other). With these changes the cooperative becomes more competitive in the regional and national markets and its economy is connected more closely with the national and international economy.

Also, the cooperative with the export of marmalades to Germany proves that the endogenous development of a local enterprise has increased considerably its presence in the international markets.

The sustainability and adaptability of the Cooperative to the new requirements: Sustainability involves the adaptability of a local enterprise to new requirements. Thus, the Cooperative until now invests in equipment with modern instruments, provides training and seminars on new technological changes but also provides ways which can help the transformation of enterprise to be more competitive (via the reduction of cost) and accordingly in the consolidation of its viability. The members know that technology allows local enterprises to use effectively local resources and simultaneously to increase their market competitiveness. These actions created the conditions for a sustainable Cooperative with endogenous local development and harmoniously included in the national, but also international economy.

New prospects?: It is a fact that a lot of women's Agritourism cooperatives were founded in the past few years, such as the Agritourism Cooperative of Women of Zagora, that contribute decisively to local development. The restoration of traditional houses, the production of traditional products, the resurgence of traditional customs are actions for local growth. Specifically, when there is the possibility of participation and activation in the cooperatives with no age-related discrimination, sex or even other, then the real possibilities of development of the region emerge. Because development is a participative process, that is to say it requires the participation of citizens in the developmental programs or in the strategies of development, it presupposes that this participation will be in the same degree and without discriminations for the all citizens independent of age or any other characteristic.
The development cannot be supported from foreigners with a given social space or from some minority of any nature (technocrats, governmental and political dignitaries). On the contrary, the persons most affected by the development programs should take active part in the determination of the type of development that they need and prefer and realise with their mass attendance in all stages of any development effort.

The future appears to work in favour of [the] genuine participative processeses. The reduction of time of work, resulting from the distribution of [technology of] information technology will release creative forces in the local societies. Moreover, the diffusion of information that has the distribution of technology strengthens possibilities that are opened by Cooperatives. This needs to be accomplished quickly as windows of opportunity are closing. The possibility for balanced development of the countryside keeping pace with the urban centres, for endogenous development and finally for sustainable development should not be lost.

The search for new prospects and the achievement of productive and social objectives are supported decisively by the briefing and training of citizens, as well as by their participation in decisions and essential attendance in the developmental activities of their region.

\section{ACKNOWLEDGMENT}

The authors are grateful to Dr. Dean MacCannell, Professor Emeritus in Environmental Design and Landscape Architecture University of California, Davis, USA, for valuable discussions.

\section{REFERENCES}

1. Blakely, E.d., 1997. Planning Local Economic Development: Theory and Practice. Sage Publications, pp: xv -xvi. London.

2. Chairman of Agritourism Cooperative of Zagora, 2007. Personal interview, with the method of not structured questionnaire.

3. Daoutopoulos, G., 2002. Seven Simple Lessons of Development. University of Macedonia, Thessaloniki. (In Greek).

4. Friedmann, J., 1991. The industrial transition: A Comprehensive Approach to Regional Development. In: Bergman, E.M. et al., Regions Reconsidered: Economic Networks, Innovation and Local Development in Industrialized Countries. London: Mansell, pp: 167- 178. 
5. Ikerd, J., 2001. Rural communities: Places without a Purpose Sustainable Farming and Rural Community Development. University of Missouri, www.undp.org/hdr.

6. Kafetzi, P., 2007. Researcher B' in the national centre of social researches for the economic social and historical development of zagora. Personal interview, with the method of not structured questionnaire.

7. Leinbach, T.R., 1992. Small Towns, Rural Linkages and Employment. Int. Regional Sci. Rev., 14 (3): 317-323. USA.

8. Municipality of Magnisia, Statistical elements of Zagora and Magnisia. Inventory, 2001. www.magnesia.gr.

9. Murdoch, J., 2000. Networks-a new paradigm of rural development? J. Rural Stud., 16: 407-419. USA.

10. Papageorgiou, K., 2004. Sustainable Economy of Cooperatives. Publisher A. Stamoulis, Athens. (In Greek).

11. Saplaoura, P., K. Apostolopoulos and H. Theodoropoulou, 2004. Investigation of possibilities of growth of mountainous regions of country: The case of further endogenous development of province of Metsovo. 3rd Interdisciplinary Inter-university Congress of Polytechnic School of Athens. The completed development in the Mountainous Regions. Theory and Act. Centre of Interdisciplinary Research from Metsovo. Institution of Development of ME.K.DE. Library ME.K.४.E., E.M.П.: 3. Athens, pp: 308-328.

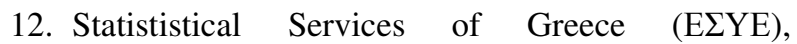
Inventory, 2001.

13. Stefanou, I. and R. Mitoula, 2004. The contribution of community frames of support and drawing of regional development of eu in the maintenance and appointment of physiognomy of greek cities. Proceeding of Congress titled, Policy of sustainable growth of cities in Greece. Ministry of Environment Planning and Public Works-E.M.P., Athens 15/9/2004.

14. Theodoropoulos, H. and E. Fafaliou, 2003. The local aspects of regional and employment strategies, Indicators issues involved in evaluation processes of developmental policies. Collective Volume Lazari A., University of Piraeus, 2: 209-231.

15. Vasquez-Barquero, A., 2002. Endogenous Development Networking, Introduction, Institutions and Cities. Publisher: Routledge, UK.

16. Voutsinos, A., 2004. An Examination of the rural tourism activities in greece, with particular reference to agri-tourist co-ops. University of Central Lancashire, Department of Tourism and Leisure Management, Preston. 